\title{
Correlates of soft drink and fruit juice consumption among Swedish adolescents
}

\author{
Karin Vågstrand ${ }^{1}$, Yvonne Linné ${ }^{1}$, Jan Karlsson ${ }^{2}$, Kristina Elfhag ${ }^{1}$ and Anna Karin Lindroos ${ }^{3}$ \\ ${ }^{1}$ Department of Medicine Huddinge, Karolinska Institutet, Karolinska University Hospital Huddinge, 14186 Stockholm, Sweden \\ ${ }^{2}$ Institute of Health and Care Sciences, Sahlgrenska Academy at Göteborgs University, Bruna Stråket 30, Sahlgrenska University \\ Hospital, 41345 Göteborg, Sweden \\ ${ }^{3}$ MRC Human Nutrition Research, Elsie Widdowson Laboratory, Fulbourn Road, Cambridge CB1 9NL, UK
}

(Received 9 December 2007 - Revised 19 August 2008 - Accepted 28 August 2008 - First published online 7 October 2008)

The aim of the study was to investigate how soft drink and fruit juice consumption in teenagers is associated with life-style, other food choices, eating behaviour and maternal characteristics. A cross-sectional study of 16-year-old girls $(n 275)$ and boys $(n 199)$ and their mothers was undertaken. Questionnaires were used to assess habitual dietary intake, eating behaviour, physical activity, smoking and educational level. Weight and height were measured. It was found that eating breakfast less than five times per week was independently associated with a high soft drink consumption in both girls and boys. A low intake of cooked meals and milk and a high intake of salty snacks were associated with soft drinks in boys only, and a low intake of fruits in girls only. A high maternal juice intake, low milk and high fruit consumption were independent correlates of fruit juice intake in both girls and boys. In girls, being a smoker, having a smoking mother, a high soft drink intake, scoring low on emotional eating and high on cognitive restraint were also associated with fruit juice intake. A low intake of soft drinks and cooked meals was associated with fruit juice intake in boys only. Neither soft drinks nor fruit juice was associated with BMI. In conclusion, a high intake of both fruit juice and soft drinks were associated with a lower intake of foods such as milk and cooked meals. It might be possible to influence fruit juice intake among teenagers by aiming at their mothers, whereas the adolescents themselves should be targeted when the aim is to reduce soft drink consumption.

Soft drinks: Fruit juice: Adolescents: Mother-child associations

Intake of sugar-containing beverages has increased during the last decade. The average consumption in Sweden of carbonated sodas, judging from food disappearance data, has increased around $100 \%$ in 15 years ${ }^{(1)}$. Similar trends are seen in most countries, for example in the USA where total sweetened beverage intake among children increased $135 \%$ between 1977 and $2001^{(2)}$. A large proportion of the consumers of sweetened beverages are likely to be young as studies have shown that the older the child ${ }^{(3,4)}$ and the younger the adult $^{(2,5)}$, the higher the soft drink consumption is.

Along with the increase in soft drink consumption, the obesity prevalence figures have increased all over the world ${ }^{(6)}$, and not surprisingly, it has been speculated that there is a causal link between soft drinks and weight status. This hypothesis has been thoroughly explored in two recent reviews ${ }^{(7,8)}$ and in one meta-analysis ${ }^{(9)}$. Although the conclusions from these reviews include calls for more research, there is enough evidence today, according to Malik et al. ${ }^{(8)}$ and Vartanian et $a l .{ }^{(9)}$, to recommend prevention strategies targeting a reduction of soft drink consumption. The mechanism for the link between sugar-sweetened beverage intake and adiposity is not entirely clear. Several possibilities have been suggested, including high fructose content and displacement of calcium-containing beverages ${ }^{(7)}$. However, the most likely explanation is that a high beverage consumption simply leads to an excessive energy intake and positive energy balance. If this energy imbalance is caused by a difference in satiety properties between liquid calories and solid foods, as shown in some studies ${ }^{(10,11)}$, or if the explanation is more complex, is yet to be proven. Previous research has mainly focused on soft drinks, but fruit juice consumption has been shown to be related to a higher body weight as well ${ }^{(12-14)}$.

Predictors and correlates for a high beverage intake have been studied before, but not extensively. Lower social status, measured as parental occupation ${ }^{(4)}$ or education plan of the child ${ }^{(15)}$, seem to be associated with a higher intake of soft drinks. In young adults, smoking and low physical activity have also been shown to be related with a higher consumption of soft drinks ${ }^{(16)}$. Adults, but not children, with a high intake of sugar-sweetened soft drinks are less restrained and report more external eating than those with a lower intake $^{(5)}$. Parents and family habits seem also to have an impact on children's soft drink consumption patterns. Parental soft drink consumption ${ }^{(17)}$, parenting practices ${ }^{(18)}$, availability of soft drinks at home $e^{(17)}$ and attitudes and norms of the parents $^{(15,18)}$ have all been shown to be associated. 
Whereas previous research has focused on socio-economic and behavioural factors, less is known about the associations between soft drinks and intake of other food groups and maternal body size. In addition, fruit juice has not previously been studied to the same extent as soft drinks. With more knowledge about the similarities and differences between soft drink and fruit juice consumption we are better equipped to address issues related to beverage consumption in intervention studies and when planning prevention strategies.

The aim of the present study is to investigate how eating behaviour, food choices, physical activity, BMI and smoking in Swedish teenagers, and education, beverage intake, smoking and BMI of their mothers, are associated with soft drink and fruit juice consumption of the teenagers.

\section{Subjects and measurements}

\section{Subjects}

Subjects were participants in the Stockholm Weight Development Study (SWEDES) ${ }^{(19)}$ with 481 adolescent children and their mothers from the Stockholm region. The recruitment base was 2342 participants of a pregnancy study (the Stockholm Pregnancy and Weight Development Study) from $1984^{(20)}$, which represented a cross-sectional sample of the women of southern Stockholm. Of these women, 1906 mother-child pairs were invited in 2001-2 and $25 \%$ of those ( $n$ 481) agreed to participate in SWEDES. Mother-child pairs that had moved away from the Stockholm area were not invited. Seven teenagers did not complete the dietary questionnaire, which left 474 subjects ( 275 girls and 199 boys) to be included in the study (see Table 1 for characteristics).

\section{Body measurements}

Weight and height, for the calculation of BMI, were measured at the clinic. Weight was measured to the nearest $0.1 \mathrm{~kg}$ with subjects standing dressed in underwear. Standing height was measured to the nearest $1.0 \mathrm{~cm}$.

\section{Dietary intake}

A dietary questionnaire originally developed for the Swedish Obese Subjects Study was used to assess dietary intake ${ }^{(21)}$. In a validation study, mean energy intake from the questionnaire did not differ significantly from estimated energy expenditure in neither normal weight nor obese adults ${ }^{(21)}$. The questionnaire has also been validated in eighteen 15-year-old adolescents (nine boys and nine girls) using doubly labelled water ${ }^{(22)}$. In both girls and boys, the reported mean energy intake did not differ significantly from measured energy expenditure. The questionnaire is based on a simplified dietary history and covers dietary intake during the past 3 months. Emphasis is placed on cooked meals and sandwiches and the questionnaire includes three coloured photographs with different amounts on the plates to assist subjects in describing portion sizes of cooked meals. Sweets (candies, chocolates) is quantified in detail and the participant can choose alternatives ranging from small, medium and larger pieces, sizes of pre-confectioned packages as sold in Sweden or per units of $100 \mathrm{~g}$. Salty snacks (crisps and cheese doodles) are also quantified by pre-confectioned package size. For intake of beverages, fruits, milk and yoghurts, a semi-quantitative approach is used, using predefined portion sizes. The amounts of all reported foods are converted into energy intake and nutrient intake per day, using food tables from the Swedish National Food Administration ${ }^{(23)}$. For more details of the questionnaire see Lindroos et al. ${ }^{(21)}$ where the entire questionnaire is published.

The questionnaire included two questions on non-alcoholic energetic beverages: (1) soft drinks (carbonated/non-carbonated sugar-sweetened soft drinks, including squash and cordial) and (2) fruit juice. Another five food groups were chosen as independent variables based on their possible relationship with beverage intake: (1) sugary foods (candies, chocolates, ice cream, cookies, cakes etc.) due to their similarity to sugar-sweetened beverages, i.e. high sugar content and small nutritional benefit; (2) salty snacks (potato crisps, cheese doodles etc.) as they are often consumed together with soft drinks; (3) milk (milk, fermented milk and yoghurt) as previous studies have shown an inverse association between milk and soft drink intake ${ }^{(9)}$; (4) fruits as we hypothesized that fruit juice might be consumed at the expense of fruit; (5) cooked meals (combined meals with meat/fish, potatoes/rice/pasta and vegetables) as we hypothesized that cooked meals might represent regular food patterns and, if so, would be inversely associated with beverages taken between meals.

The participants were also asked how many times per week they eat breakfast, choosing from never, one to four times

Table 1. Description of the participants

\begin{tabular}{|c|c|c|c|c|c|c|c|c|c|}
\hline & \multicolumn{3}{|c|}{ Girls (n 275) } & \multicolumn{3}{|c|}{ Boys ( $n$ 199) } & \multicolumn{3}{|c|}{ Mothers $(n 474)$} \\
\hline & Mean or $n$ & SD or $\%$ & Min-max & Mean or $n$ & SD or $\%$ & Min-max & Mean or $n$ & SD or $\%$ & Min-max \\
\hline Age (years) & $16 \cdot 8$ & 0.4 & $15 \cdot 9-17 \cdot 8$ & $16 \cdot 9$ & 0.4 & $16 \cdot 1-17 \cdot 7$ & $46 \cdot 8$ & $4 \cdot 4$ & $34.7-61.5$ \\
\hline Weight $(\mathrm{kg})$ & $59 \cdot 6$ & $9 \cdot 1$ & $43 \cdot 8-94 \cdot 2$ & $68 \cdot 7$ & $12 \cdot 0$ & $46 \cdot 8-116 \cdot 2$ & $68 \cdot 4$ & $12 \cdot 5$ & $41 \cdot 9-133 \cdot 2$ \\
\hline Height $(\mathrm{cm})$ & 167 & 6 & $152-185$ & 180 & 6 & $161-195$ & 167 & 6 & $147-183$ \\
\hline $\operatorname{BMI}\left(\mathrm{kg} / \mathrm{m}^{2}\right)$ & 21.5 & 3.1 & $15 \cdot 8-36 \cdot 9$ & $21 \cdot 1$ & $3 \cdot 2$ & $15 \cdot 6-33 \cdot 2$ & $24 \cdot 6$ & $4 \cdot 3$ & $16 \cdot 8-50 \cdot 1$ \\
\hline Overweight subjectsł‡ & 27 & 11 & & 28 & 15 & & 151 & 34 & \\
\hline Obese subjects†§ & 7 & 3 & & 5 & 3 & & 40 & 9 & \\
\hline $\begin{array}{l}\text { Mothers with college or } \\
\text { university degreet }\end{array}$ & & & & & & & 285 & 60 & \\
\hline Smokers $†$ & 45 & 16 & & 18 & 9 & & 64 & 14 & \\
\hline
\end{tabular}

Min-max, minimum to maximum.

† Values are number and percentage.

$\ddagger$ In mothers, overweight is $\mathrm{BMI}>25$; in children, overweight is IsoBMI $>25$. The classification system for children recommended by the International Obesity Task Force ${ }^{(46)}$. $\S$ In mothers, obesity is $\mathrm{BMI}>30$; in children, obesity is Iso $\mathrm{BMI}>30$. 
per week, five or six times per week or daily. The first two categories and the last two were combined in the analyses ( seldom $=0-4$, often $=5-7$ times $/$ week). In addition, the participants were asked whether they usually eat their meals at the same time every day or not (yes/no).

\section{Physical activity}

The physical activity questionnaires were IPAQ ${ }^{(24)}$ for the mothers and SAPAQ ${ }^{(25)}$ for the adolescents. These questionnaires are designed to collect information on frequency, duration and intensity of physical activity (PA) in three different domains (school/work, self-powered transportation and leisure time) during the last $7 \mathrm{~d}$. Total metabolic energy turnover minutes calculated from the SAPAQ questionnaire were significantly correlated to the total metabolic energy turnover minutes assessed by accelerometry in a subgroup of the adolescents. This indicates a reasonable validity of the questionnaire for assessing the total volume of physical activity ${ }^{(25)}$.

\section{Three Factor Eating Questionnaire - Revised 18 Items}

Eating behaviour was assessed by the the Three Factor Eating Questionnaire - Revised 18 Items (TFEQ-R18) ${ }^{(26)}$ which is a revised short-form version of the The Three Factor Eating Questionnaire, a frequently used instrument for describing eating behaviour $^{(27)}$. The short-form TFEQ-R18 is suggested as a psychometrically valid instrument suitable for use in largescale studies ${ }^{(26)}$. The TFEQ-R18 covers three eating behaviour domains: the Cognitive restraint scale (six items) assesses conscious control over food intake in order to influence body

Table 2. Dietary variables $†$

(Mean values, standard deviations and median values) weight and body shape; the Emotional eating scale (six items) measures the tendency to overeat in relation to negative mood states, e.g. when feeling lonely, anxious or depressed; and the Uncontrolled eating scale (nine items) assesses the propensity to lose control over eating when feeling hungry or when exposed to external stimuli. Higher scores indicate greater Cognitive restraint, Emotional eating, or Uncontrolled eating.

\section{Socio-economic data}

Educational level of the mothers was assessed by the question, 'What is your highest completed education?', and five response alternatives based on the Swedish school system. The response alternatives were combined into a dichotomous variable; high and low education (university/college education or not). Both mothers and children were asked about their smoking habits. The twenty children who stated to be ex-smokers were all categorized as smokers, while ex-smokers among mothers were categorized as non-smokers.

\section{Statistics}

SPSS version 14.0 (SPSS Inc., Chicago, IL, USA) was used for the statistical analyses. Results with a $P$ value under 0.05 were considered statistically significant. Mann-Whitney $U$ test and Fisher's exact test were used to test differences between girls and boys in Table 2. Bivariate Pearson's correlation was used in the analyses in Tables 3 and 4. Linear multiple regression analyses were used in Tables 5 and 6 . Not normally distributed variables, defined as skewness $>2$ or kurtosis $>7^{(28)}$, were either log- or square root-transformed

\begin{tabular}{|c|c|c|c|c|c|c|}
\hline & \multicolumn{3}{|c|}{ Girls (n 275) } & \multicolumn{3}{|c|}{ Boys ( $n 199)$} \\
\hline & Mean & SD & Median & Mean & SD & Median \\
\hline \multicolumn{7}{|l|}{ Reported food intake } \\
\hline Soft drinks (kJ/d) & 250 & 280 & 200 & 490 & 540 & $280^{\star \star \star}$ \\
\hline Fruit juice $(\mathrm{kJ} / \mathrm{d})$ & 390 & 440 & 240 & 510 & 520 & $420^{\star}$ \\
\hline Cooked meals (kJ/d) & 2440 & 1170 & 2360 & 3830 & 1900 & $3510^{\star * *}$ \\
\hline Milk (kJ/d) & 1270 & 1050 & 1040 & 1890 & 1320 & $1690^{\star * *}$ \\
\hline Salty snacks (kJ/d) & 320 & 320 & 250 & 460 & 450 & $320^{\star \star *}$ \\
\hline Sugary foods (kJ/d) & 1440 & 1470 & 1120 & 1670 & 1380 & $1440^{\star \star}$ \\
\hline Fruits $(\mathrm{kJ} / \mathrm{d})$ & 430 & 330 & 350 & 470 & 500 & 320 \\
\hline Total energy intake (kJ/d) & 10150 & 4340 & 9370 & 14580 & 5440 & $3500^{\star * *}$ \\
\hline \multicolumn{7}{|l|}{ Physical activity } \\
\hline $\operatorname{MET}(\mathrm{min} / \mathrm{d})$ & 940 & 770 & 810 & 1300 & 1140 & $1060^{\star \star \star}$ \\
\hline \multicolumn{7}{|l|}{ Eating behaviour } \\
\hline Cognitive restraint $\ddagger$ & 30 & 21 & 28 & 15 & 16 & $11^{\star \star \star}$ \\
\hline Emotional eating $\ddagger$ & 25 & 23 & 22 & 8 & 14 & $0^{\star \star *}$ \\
\hline Uncontrolled eating $\ddagger$ & 35 & 17 & 33 & 31 & 17 & $30^{\star \star}$ \\
\hline \multicolumn{7}{|l|}{ Reported food intake of mother } \\
\hline Soft drinks (kJ/d) & 80 & 200 & 0 & 50 & 110 & 0 \\
\hline Fruit juice $(\mathrm{kJ} / \mathrm{d})$ & 240 & 370 & 120 & 220 & 300 & 120 \\
\hline Total El (kJ/d) & 8320 & 2100 & 8230 & 8130 & 2310 & 7710 \\
\hline Subjects not eating meals at the same time every day§ & 118 & 43 & & 69 & $35^{\star}$ & \\
\hline Subjects eating breakfast $<5$ times/week§ & 40 & 14 & & 20 & 10 & \\
\hline
\end{tabular}

MET, metabolic energy turnover.

Values were significantly different from those of the girls (Mann-Whitney/Fisher's exact test): ${ }^{\star} P<0.05,{ }^{\star \star} P<0.01,{ }^{\star \star \star} P<0.001$

†For details of subjects and procedures, see Table 1 and Subjects and measurements.

$\ddagger$ Values are transformed scale scores showing percentage of total possible raw scale scores.

$\S$ Values are number and percentage of total. 
Table 3. Correlation coefficients or $t$ values for possible correlates of soft drink consumptiont‡

\begin{tabular}{|c|c|c|c|c|}
\hline & \multicolumn{2}{|c|}{ Girls ( $n$ 275) } & \multicolumn{2}{|c|}{ Boys ( $n$ 199) } \\
\hline & $r$ & $P$ & $r$ & $P$ \\
\hline \multicolumn{5}{|l|}{ Lifestyle } \\
\hline BMI & -0.04 & 0.50 & -0.07 & 0.32 \\
\hline Physical activity & 0.00 & 0.95 & 0.02 & 0.82 \\
\hline Educational level, mother $(0=$ low, $1=$ high $)$ & -0.12 & 0.05 & -0.09 & 0.19 \\
\hline Smoking, child $(0=$ no, $1=$ yes $)$ & 0.02 & 0.68 & 0.17 & 0.02 \\
\hline Smoking, mother $(0=$ no, $1=$ yes $)$ & -0.05 & 0.42 & 0.06 & 0.38 \\
\hline \multicolumn{5}{|l|}{ Eating habits } \\
\hline Intake of cooked mealst & -0.16 & 0.01 & -0.20 & 0.005 \\
\hline Intake of milkt & $-0 \cdot 10$ & 0.09 & -0.19 & 0.008 \\
\hline Intake of salty snacks $\dagger$ & 0.00 & 0.96 & 0.21 & 0.003 \\
\hline Intake of sugary foodst & 0.18 & 0.002 & 0.06 & 0.36 \\
\hline Intake of fruits† & -0.28 & $<0.001$ & $-0 \cdot 16$ & 0.02 \\
\hline Intake of fruit juicet & 0.08 & 0.22 & -0.11 & 0.11 \\
\hline Eating meals at the same time every day $(0=$ no, $1=$ yes $)$ & -0.17 & 0.006 & -0.06 & 0.38 \\
\hline Breakfast habits $(0=$ seldom, $1=$ often $)$ & -0.24 & $<0.001$ & -0.20 & 0.004 \\
\hline Uncontrolled eating & -0.01 & 0.94 & -0.05 & 0.46 \\
\hline Emotional eating & 0.01 & 0.90 & -0.06 & 0.40 \\
\hline Cognitive restraint & -0.09 & 0.13 & -0.10 & 0.17 \\
\hline \multicolumn{5}{|l|}{ Mother } \\
\hline BMI & 0.13 & 0.03 & 0.04 & 0.53 \\
\hline Age & -0.04 & 0.53 & -0.01 & 0.90 \\
\hline Intake of soft drinks $†$ & 0.13 & 0.03 & 0.08 & 0.25 \\
\hline
\end{tabular}

† Measured as the residuals of the correlation between the actual food group and total energy intake. $\ddagger$ For details of subjects and procedures, see Table 1 and Subjects and measurements.

(depending on which method produced less skewness). If a variable included zero-values, the constant 10 was added before log-transformation.

To make the food group variables independent of total energy intake, residuals from separate linear regression models between total energy intake and the respective food group was calculated and used in the correlation and regression models instead of absolute intake (the residual method) ${ }^{(29)}$.

The included independent variables were chosen to reflect three different dimensions: (1) life-style/socio-economy, (2) eating habits and (3) the impact of the mother. Firstly, all

Table 4. Correlation coefficients or $t$ values for possible correlates of fruit juice consumption $† \ddagger$

\begin{tabular}{|c|c|c|c|c|}
\hline & \multicolumn{2}{|c|}{ Girls ( $n$ 275) } & \multicolumn{2}{|c|}{ Boys ( $n$ 199) } \\
\hline & $r$ & $P$ & $r$ & $P$ \\
\hline \multicolumn{5}{|l|}{ Lifestyle } \\
\hline BMI & 0.01 & 0.85 & -0.05 & 0.48 \\
\hline Physical activity & -0.03 & 0.61 & -0.10 & $0 \cdot 19$ \\
\hline Educational level, mother $(0=$ low, $1=$ high $)$ & 0.03 & 0.64 & 0.06 & 0.44 \\
\hline Smoking, child $(0=$ no, $1=$ yes $)$ & $0 \cdot 14$ & 0.02 & -0.04 & 0.58 \\
\hline Smoking, mother $(0=$ no, $1=$ yes $)$ & $0 \cdot 12$ & 0.06 & 0.04 & 0.62 \\
\hline \multicolumn{5}{|l|}{ Eating habits } \\
\hline Intake of cooked meals $†$ & -0.13 & 0.03 & -0.15 & 0.03 \\
\hline Intake of milk $\dagger$ & $-0 \cdot 10$ & $0 \cdot 10$ & -0.23 & 0.001 \\
\hline Intake of salty snacks $†$ & $-0 \cdot 10$ & 0.11 & 0.05 & 0.51 \\
\hline Intake of sugary foods $\dagger$ & -0.06 & 0.29 & $0 \cdot 15$ & 0.04 \\
\hline Intake of fruitst & $0 \cdot 10$ & 0.08 & 0.22 & 0.002 \\
\hline Intake of soft drinks $\dagger$ & 0.08 & 0.22 & -0.11 & $0 \cdot 11$ \\
\hline Eating meals at the same time every day $(0=$ no, $1=$ yes $)$ & -0.02 & 0.78 & -0.07 & 0.32 \\
\hline Breakfast habits $(0=$ seldom, $1=$ often $)$ & 0.00 & 0.99 & 0.12 & $0 \cdot 11$ \\
\hline Uncontrolled eating & -0.08 & $0 \cdot 19$ & 0.07 & 0.32 \\
\hline Emotional eating & -0.05 & 0.39 & 0.11 & $0 \cdot 13$ \\
\hline Cognitive restraint & $0 \cdot 10$ & 0.11 & $0 \cdot 11$ & $0 \cdot 11$ \\
\hline \multicolumn{5}{|l|}{ Mother } \\
\hline BMI & -0.08 & 0.17 & -0.01 & 0.91 \\
\hline Age & -0.04 & 0.57 & 0.00 & 0.98 \\
\hline Intake of fruit juice $†$ & 0.30 & $<0.001$ & 0.30 & $<0.001$ \\
\hline
\end{tabular}

† Measured as the residuals of the correlation between the actual food group and total energy intake. ‡For details of subjects and procedures, see Table 1 and Subjects and measurements. 
Table 5. Correlates of soft drink consumptiont in a multivariate regression modelł

\begin{tabular}{lcc}
\hline & Standardized $\beta$ & $P$ \\
\hline Girls & & \\
$\quad$ Intake of fruits $\dagger$ & -0.26 & $<0.001$ \\
Breakfast $(0=$ seldom, $1=$ often) & -0.23 & $<0.001$ \\
$\quad$ Adjusted $R^{2}$ & 0.12 & \\
Boys & & \\
Intake of cooked meals $\dagger$ & -0.23 & 0.001 \\
Intake of milk $\dagger$ & -0.20 & 0.006 \\
Intake of fruit juice $\dagger$ & -0.18 & 0.01 \\
Breakfast $(0=$ seldom, $1=$ often) & -0.15 & 0.02 \\
Intake of salty snacks $\dagger$ & 0.14 & 0.05 \\
Adjusted $R^{2}$ & 0.14 & \\
\end{tabular}

† Measured as the residuals of the correlation between the actual food group and total energy intake.

\#For details of subjects and procedures, see Table 1 and Subjects and measurements.

variables were included in the regression model. The model was examined for possible multicollinearity. Lowest tolerance values were found for emotional eating and cognitive restraint $(0 \cdot 65)$, but most other variables had values about $0 \cdot 9$. Residual plots were studied for heteroscedasticity and normal distribution, and partial plots for non-linear relationships and outliers, without any unwanted results. In all, the models seem to meet the assumptions of linear regression well. In the next step, only the variables with a $P$ value less than $0 \cdot 3$ were kept in the model. Thereafter the variables were excluded in a stepwise procedure until only variables with $P$ values less than 0.05 were left (Tables 5 and 6).

The study was approved by the local Ethics Committee of Huddinge University Hospital. Informed consent was obtained from each mother and verbal consent ascertained from each child.

\section{Results}

The energy from included food groups was not normally distributed, due to a few individuals with a very large

Table 6. Correlates of fruit juice consumption† in a multivariate regression model

\begin{tabular}{|c|c|c|}
\hline & Standardized $\beta$ & $P$ \\
\hline \multicolumn{3}{|l|}{ Girls } \\
\hline Intake of fruit juice, mother† & 0.32 & $<0.001$ \\
\hline Cognitive restraint & 0.14 & 0.02 \\
\hline Emotional eating & -0.14 & 0.02 \\
\hline Smoking, child & $0 \cdot 13$ & 0.02 \\
\hline Intake of soft drinks† & 0.13 & 0.02 \\
\hline Intake of milk† & -0.13 & 0.03 \\
\hline Intake of fruits $†$ & 0.13 & 0.03 \\
\hline Smoking, mother & 0.12 & 0.03 \\
\hline Adjusted $R^{2}$ & 0.16 & \\
\hline \multicolumn{3}{|l|}{ Boys } \\
\hline Intake of fruit juice, mother† & 0.30 & $<0.001$ \\
\hline Intake of milk† & -0.25 & $<0.001$ \\
\hline Intake of cooked meals & -0.23 & $<0.001$ \\
\hline Intake of fruits $†$ & $0 \cdot 21$ & 0.001 \\
\hline Intake of soft drinks† & -0.17 & 0.01 \\
\hline Adjusted $R^{2}$ & 0.23 & \\
\hline
\end{tabular}

consumption (Table 2). Boys reported a significantly higher intake of total energy and of all included food groups. Girls reported a more problematic eating behaviour with more cognitive restraint, emotional and uncontrolled eating, and less regular meals than boys did. In boys, the reported median intake of both soft drinks and fruit juice in boys was $200 \mathrm{~g} / \mathrm{d}$. Girls had a median intake of $140 \mathrm{~g}$ soft drink and $110 \mathrm{~g}$ fruit juice/d.

The reported energy intake from all food groups was strongly correlated to total energy intake (soft drinks, $r$ 0.5; milk, $r 0.5$; cooked meals, $r 0.5$; salty snacks, $r 0.4$; sugary foods, $r$ 0.6; fruits, $r 0.3$; fruit juice, $r 0 \cdot 3$ ). The energyadjusted food group variables were not associated with total energy intake.

Intake of soft drinks was negatively correlated with cooked meals and fruits, and associated with a low breakfast frequency in both girls and boys, as shown in Table 3. All other significant correlations differed by gender, although the soft drink-salty snack association was the only one that differed significantly ( $P=0.006$ for interaction). Fruit juice consumption correlated negatively with the intake of cooked meals and positively with the mother's fruit juice consumption in both girls and boys (Table 4). In boys only, a high consumption of fruit juice was also correlated with a high intake of sugary foods $(P=0.04$ for gender interaction) and a low intake of milk ( $P=0.04$ for gender interaction). Smoking girls, but not smoking boys, had a higher intake of fruit juice than non-smokers did, but there was no statistically significant gender interaction.

Table 5 shows the final multiple regression models for the correlates of soft drink consumption. The only significant correlates in girls were a low intake of fruit and breakfast less than five times per week. In boys, a low consumption of cooked meals, milk and fruit juice, breakfast less than five times per week and a high intake of salty snacks were all significant correlates.

The adjusted correlates of fruit juice consumption are displayed in Table 6 . The strongest correlate in both girls and boys were the mothers' reported intake of fruit juice. A high fruit juice intake was also associated with a low intake of milk and a high intake of fruits in both girls and boys. In girls, being a smoker, having a smoking mother, low emotional eating scores and high cognitive restraint scores were also significantly associated with fruit juice intake, whereas a low intake of cooked meals was independently associated with fruit juice in boys. Soft drink and fruit juice consumption were associated with each other but with opposite direction in girls and boys. The association was negative in boys and positive in girls $(P=0.04$ for interaction $)$.

\section{Discussion}

In the present study, we have analysed correlates of soft drink and fruit juice intake among adolescents. Food patterns differed between adolescents with a higher intake of soft drinks and fruit juice compared to those with a lower intake. A high intake of soft drinks was associated with lower breakfast frequency in both girls and boys. Boys with high soft drink consumption also reported a lower intake of cooked meals and milk, and a higher intake of salty snack foods. Girls with high soft drink consumption reported a lower intake of fruits. 
The strongest correlate of fruit juice consumption in both girls and boys was the mothers' intake of fruit juice. Fruit juice consumption was also associated with a low intake of milk and a high intake of fruits in both girls and boys, whereas a low intake of cooked meals was associated with higher fruit juice intake in boys only. Boys seemed to drink fruit juice instead of soft drinks, whereas the two beverages were positively related to each other in girls.

It is a worry that both these beverages were consumed at the expense of milk consumption. Milk products are an important calcium source in the diet and have also been found to be negatively correlated to the intake of sugary drinks in many previous studies ${ }^{(9)}$. A low intake of milk during adolescence is critical as it may jeopardize the accrual of maximal peak bone mass ${ }^{(30)}$.

The reduced intake of cooked meals is also a worry, since cooked meals often have higher and, most of all, a more varied nutritious content than these beverages. In addition, the large intake of sugary foods and salty snacks and the low intake of fruits accompanying soft drinks even further decrease the quality of the diet. It is interesting to notice that fruit juice, although often considered a healthy choice and associated with a higher fruit intake, was associated with a lower intake of milk and cooked meals.

Besides the risk of a lower intake of various nutrients, there are other consequences with a high intake of sugar-sweetened beverages, such as an increased risk of caries ${ }^{(31)}$. A high intake of sugar has also been discussed as a contributing factor for the development of insulin resistance ${ }^{(32)}$ and hypertriglyceridaemia ${ }^{(33)}$.

A recent Belgian study among adolescents (13-18 years $)^{(34)}$ found that those who had good breakfast habits (a combination of good quality, large quantity and high frequency) had a higher intake of fruit juice and lower intake of soft drinks than those with bad breakfast habits. In the present study, juice consumption was not associated with breakfast habits, suggesting that fruit juice in this population is consumed throughout the day rather than at breakfast. The present soft drink results, however, were in concordance with the Belgian study where a low breakfast frequency was one of the strongest correlates. The importance of good breakfast habits has been observed in many studies ${ }^{(35,36)}$, including the SWEDES study ${ }^{(37)}$, and seems to be associated with healthier food choices during the day.

The strongest correlate of fruit juice consumption in both girls and boys was the mother's consumption. Soft drink consumption, on the other hand, was more or less independent of the mother's intake. This is in contrast to two previous studies where soft drink consumption of mothers and children, aged $8-13$ years, was correlated ${ }^{(17,38)}$, but these studies are not entirely comparable to the present study due to the younger age group. Soft drinks are perhaps bought and consumed outside the home by the teenagers in the present study, while fruit juice might be found at home where it is consumed by the whole family.

Fruit juice is generally considered a healthy product equivalent with fruits, whereas soft drinks are perceived as bad for health and weight. This opinion of fruit juice is probably mirrored in the positive association between fruit juice and cognitive restraint and the negative association with emotional eating. It has been shown in earlier studies that restrained eaters tend to choose more healthy foods such as fruits and vegetables and less sweet beverages ${ }^{(5,38,39)}$. The positive correlation between smoking and fruit juice suggests that fruit juice is not consumed by health-conscious individuals, but rather by weight-conscious individuals.

Another concern is that restrained eaters have, by definition, an awareness of what one should and should not eat, which might lead to an underreporting of unhealthy foods. There is often an overrepresentation of restrained eaters among underreporters of energy intake ${ }^{(40)}$, including in the present study (unpublished results). It is possible that restrained eaters actually have a lower intake of fruit juice and a higher intake of soft drinks than reported.

Concerns have been raised that a high intake of sweet beverages might lead to overweight and obesity ${ }^{(8,9)}$. One possible explanation is that these beverages have a tendency to be consumed on top of other foods, leading to an increased energy intake $^{(11)}$. It is noticeable that both fruit juice and soft drinks were negatively correlated with milk and cooked meals in the present study, suggesting that the intake of beverages was compensated, at least partly, by a decrease in energy from other sources. Hence, the present study does not support the hypothesis that beverages are consumed without a compensatory decrease of other foods.

In a large Swedish national survey from 1997 the mean soft drink intake among women, aged 17-24 years, was $289 \mathrm{~g} / \mathrm{d}$ and among young men $447 \mathrm{~g} / \mathrm{d}^{(41)}$ whereas the fruit juice intake (including nectar) was twice or four times lower, 134 and $105 \mathrm{~g} / \mathrm{d}$ for women and men, respectively. This can be compared with the mean soft drink intake of 180 and $360 \mathrm{~g} /$ $\mathrm{d}$ and fruit juice intake of 190 and $250 \mathrm{~g} / \mathrm{d}$ (for girls and boys, respectively) in the present study. Even though the present study population was reporting surprisingly low soft drink consumption, the fruit juice intake was more expected. A recent study of 11-year-old children from different European countries, including Sweden, found similar fruit juice intake to the the present study: $209 \mathrm{~g} / \mathrm{d}$ for girls and $215 \mathrm{~g} / \mathrm{d}$ for boys, although no assessment of soft drink consumption was done ${ }^{(42)}$. It is possible that the relatively low intake of soft drinks in the present study could be explained by having a selective study population. Our mothers have a higher education than the general population $(60 \%$ have a university/college degree compared to $25 \%$ of women in the general Swedish population ${ }^{(43)}$ ), and there is some evidence that higher education is associated with healthier food habits ${ }^{(44,45)}$. It is possible that correlates of beverage consumption are dependent on educational level, but this has not, to our knowledge, been studied.

Another limitation of the present study is the cross-sectional design which means we cannot draw any conclusions about causality. However, our analyses are informative and will increase the understanding of the context in which these beverages are taken and by whom. Since the increased awareness of sweet beverages as a cause for weight gain has increased, this kind of information is important.

The present study is further limited by the accuracy of the reported dietary intake, something shared by all studies using diet assessments. However, in contrast to many other studies on dietary correlates ${ }^{(4,5,15-17)}$ we have information on the entire dietary intake, which makes it possible to adjust for total energy intake. 
To conclude, high soft drink consumption seems to be part of a less favourable life-style including low breakfast frequency, a high intake of salty snacks and a low intake of calcium-rich products and fruits. High fruit juice consumption was also associated with some elements of a less healthy life-style, including smoking, a high intake of soft drinks (girls) and a lower intake of milk. However, fruit juice seems to be consumed in a better context than soft drinks. Nevertheless, there are reasons to include fruit juice consumption in future research when studying the consequences of beverage intake. Additionally, it might be possible to reduce fruit juice intake among teenagers by aiming at their mothers, whereas the adolescents themselves should be targeted when the aim is to reduce soft drink consumption.

\section{Acknowledgements}

The data collection phase of this study was funded by the European Commission, Quality of Life and Management of Living Resources, Key Action 1 'Food, nutrition and health' programme as part of the project entitled 'Dietary and genetic influences on susceptibility or resistance to weight gain on a high fat diet' (QLK1-2000-00 515). There are no known conflicts of interest. K. V. performed all analyses, interpreted the data and wrote the paper. A. K. L. assisted with interpreting the data and writing the paper. J. K. and K. E. contributed to the discussion of results, whereas Y. L. initiated the study.

\section{References}

1. Jordbruksverke (2005) Yearbook of Agricultural Statistics Including Food Statistics. Örebro: Swedish Department of Agriculture.

2. Nielsen SJ \& Popkin BM (2004) Changes in beverage intake between 1977 and 2001. Am J Prev Med 27, 205-210.

3. Striegel-Moore RH, Thompson D, Affenito SG, et al. (2006) Correlates of beverage intake in adolescent girls: the National Heart, Lung, and Blood Institute Growth and Health Study. J Pediatr 148, 183-187.

4. Vereecken CA, Inchley J, Subramanian SV, et al. (2005) The relative influence of individual and contextual socio-economic status on consumption of fruit and soft drinks among adolescents in Europe. Eur J Public Health 15, 224-232.

5. Elfhag K, Tynelius P \& Rasmussen F (2007) Sugar-sweetened and artificially sweetened soft drinks in association to restrained, external and emotional eating. Physiol Behav 91, $191-195$

6. Wang Y \& Lobstein T (2006) Worldwide trends in childhood overweight and obesity. Int $J$ Pediatr Obes 1, 11-25.

7. Bachman CM, Baranowski T \& Nicklas TA (2006) Is there an association between sweetened beverages and adiposity? Nutr Rev 64, 153-174.

8. Malik VS, Schulze MB \& Hu FB (2006) Intake of sugarsweetened beverages and weight gain: a systematic review. Am J Clin Nutr 84, 274-288.

9. Vartanian LR, Schwartz MB \& Brownell KD (2007) Effects of soft drink consumption on nutrition and health: a systematic review and meta-analysis. Am J Public Health 97, 667-675.

10. DiMeglio DP \& Mattes RD (2000) Liquid versus solid carbohydrate: effects on food intake and body weight. Int $J$ Obes Relat Metab Disord 24, 794-800.
11. Rolls BJ, Kim S \& Fedoroff IC (1990) Effects of drinks sweetened with sucrose or aspartame on hunger, thirst and food intake in men. Physiol Behav 48, 19-26.

12. Bes-Rastrollo M, Sanchez-Villegas A \& Gomez-Gracia E (2006) Predictors of weight gain in a Mediterranean cohort: the Seguimiento Universidad de Navarra Study 1. Am J Clin Nutr 83, 362-370; quiz 394-395.

13. Dennison BA, Rockwell HL \& Baker SL (1997) Excess fruit juice consumption by preschool-aged children is associated with short stature and obesity. Pediatrics 99, 15-22.

14. Sanigorski A, Bell A \& Swinburn B (2007) Association of key foods and beverages with obesity in Australian schoolchildren. Public Health Nutr 10, 152-157.

15. Bere E, Sorli Glomnes E, Te Velde SJ, et al. (2007) Determinants of adolescents' soft drink consumption. Public Health Nutr 10, 1-8.

16. Kvaavik E, Andersen LF \& Klepp KI (2005) The stability of soft drinks intake from adolescence to adult age and the association between long-term consumption of soft drinks and lifestyle factors and body weight. Public Health Nutr 8, 149-157.

17. Grimm GC, Harnack L \& Story M (2004) Factors associated with soft drink consumption in school-aged children. $J \mathrm{Am}$ Diet Assoc 104, 1244-1249.

18. de Bruijn GJ, Kremers SP, de Vries H, et al. (2007) Associations of social-environmental and individual-level factors with adolescent soft drink consumption: results from the SMILE study. Health Educ Res 22, 227-237.

19. Vagstrand K (2008) Eating habits among adolescents and their mothers - SWEDES Doctoral thesis, Karolinska Institutet. http://diss.kib.ki.se/2008/978-91-7357-524-9/thesis. pdf

20. Öhlin A \& Rössner S (1996) Factors related to body weight changes during and after pregnancy: the Stockholm Pregnancy and Weight Development Study. Obes Res 4, 271-276.

21. Lindroos AK, Lissner L \& Sjöström L (1993) Validity and reproducibility of a self-administered dietary questionnaire in obese and non-obese subjects. Eur J Clin Nutr 47, 461-481.

22. Lindroos AK, Lissner L \& Sjöström L (1995) A dietary questionnaire for obese people - development and application. In 6th European Congress on Obesity May 31-June 3, 1995, Copenhagen, Denmark. Int J Obes Relat Metab Disord 19, Suppl. 2, 75 (abstract).

23. Livsmedelsverket (1986) Food Composition Tables, 2nd ed. Stockholm: Liber Tryck AB.

24. Craig C, Marshall A, Sjostrom M, et al. (2003) International physical activity questionnaire: 12-country reliability and validity. Med Sci Sports Exerc 35, 1381-1395.

25. Ekelund U, Neovius M, Linne Y, et al. (2006) The criterion validity of a last 7-day physical activity questionnaire (SAPAQ) for use in adolescents with a wide variation in body fat: the Stockholm Weight Development Study. Int $J$ Obes 30, 1019-1021.

26. Karlsson J, Persson L, Sjöström L, et al. (2000) Psychometric properties and factor structure of the Three-Factor Eating Questionnaire (TFEQ) in obese men and women. Results from the Swedish Obese Subjects (SOS) study. Int J Obes Relat Metab Disord 24, 1715-1725.

27. Stunkard A \& Messick S (1985) The Three Factor Eating Questionnaire to measure dietary restraint, disinhibition and hunger. J Psychosomatic Res 29, 71-83.

28. Curran P, West S \& Finch J (1996) The robustness of test statistics to nonnormality and specification error in confirmatory factor analysis. Psych Methods 1, 16-29.

29. Willett W (1998) Nutritional epidemiology. In Monographs in Epidemiology and Biostatistics, vol. 30, pp. 288-291. New York: Oxford University Press. 
30. Wyshak G (2000) Teenaged girls, carbonated beverage consumption, and bone fractures. Arch Pediatr Adolesc Med 154, 610-613.

31. Birkhed D (1990) Behavioural aspects of dietary habits and dental caries. Caries Res 24, 27-35.

32. Willett W, Manson J \& Liu S (2002) Glycemic index, glycemic load, and risk of type 2 diabetes. Am J Clin Nutr 76, 274S-280S.

33. Fried SK \& Rao SP (2003) Sugars, hypertriglyceridemia, and cardiovascular disease. Am J Clin Nutr 78, 873S-880S.

34. Matthys C, De Henauw S, Bellemans M, et al. (2007) Breakfast habits affect overall nutrient profiles in adolescents. Public Health Nutr 10, 413-421.

35. Wing RR \& Hill JO (2001) Successful weight loss maintenance. Annu Rev Nutr 21, 323-341.

36. Sjöberg A (2004) Food habits in Swedish adolescents. Doctorial thesis, Göteborg University.

37. Vagstrand K, Barkeling B, Forslund HB, et al. (2007) Eating habits in relation to body fatness and gender in adolescents - results from the 'SWEDES' study. Eur J Clin Nutr 61, 517-525.

38. Elfhag K, Tholin S \& Rasmussen F (2008) Consumption of fruit, vegetables, sweets and soft drinks are associated with psychological dimensions of eating behaviour in parents and their 12-year-old children. Public Health Nutr 11, 1-10.

39. de Lauzon B, Romon M, Deschamps V, et al. (2004) The ThreeFactor Eating Questionnaire-R18 is able to distinguish among different eating patterns in a general population. $J$ Nutr 134, $2372-2380$.
40. Maurer J, Taren D, Teixeira P, et al. (2006) The psychosocial and behavioral characteristics related to energy misreporting. Nutr Rev 64, 53-66.

41. Becker W \& Pearson M (1997) Kostvanor och näringsintag i Sverige (Food habits and nutritional intake in Sweden), pp. 33-109. Uppsala: Livsmedelsverket. http://www.slv.se/upload/dokument/ Rapporter/Mat_och_nu trition/riksmat.pdf

42. Yngve A, Wolf A, Poortvliet E, et al. (2005) Fruit and vegetable intake in a sample of 11-year-old children in 9 European countries: the Pro Children Cross-sectional Survey. Ann Nutr Metab 49, 236-245.

43. SCB (2003) Undersökning av levandsförhållanden (ULF) i Sverige (Survey of living conditions in Sweden). Stockhdm: Statistics Sweden. http://www.scb.se/templates/Product_12199.asp

44. Hulshof KF, Brussaard JH, Kruizinga AG, et al. (2003) Socioeconomic status, dietary intake and 10 y trends: the Dutch National Food Consumption Survey. Eur J Clin Nutr 57, $128-137$.

45. Kant AK \& Graubard BI (2007) Secular trends in the association of socio-economic position with self-reported dietary attributes and biomarkers in the US population: National Health and Nutrition Examination Survey (NHANES) 1971-1975 to NHANES 1999-2002. Public Health Nutr 10, $158-167$.

46. Cole TJ, Bellizzi MC, Flegal KM, et al. (2000) Establishing a standard definition for child overweight and obesity worldwide: international survey. Br Med J 320, 1240-1243. 